\title{
Recovery of valuable metals from mining and mineral processing waste
}

\author{
Marinela Panayotova ${ }^{{ }^{*}}$ and Vladko Panayotov ${ }^{1,2}$ \\ ${ }^{1}$ University of Mining and Geology, Sofia, 1700, Bulgaria. \\ ${ }^{2}$ Technical Sciences, Bulgarian Academy of Sciences, Sofia, 100, Bulgaria.
}

\begin{abstract}
Ammonia-thiosulfate-copper leaching, aided by a direct current electrochemical impact, is proposed to extract gold $(\mathrm{Au})$, silver $(\mathrm{Ag})$ and copper $(\mathrm{Cu})$ from old flotation tailings mixed with waste rock. Over $80 \%$ of $\mathrm{Au}$ available in the waste material and over $75 \%$ of $\mathrm{Cu}$ and $\mathrm{Ag}$ were extracted into the pregnant leach solution (PLS) at room temperature. Electrowinning from that PLS recovered around $92 \%$ of $\mathrm{Au}$ and $\mathrm{Cu}$, and about $87 \%$ of $\mathrm{Ag}$ in the cathode deposit that is suitable for further metallurgical refining. The results are better, compared to leaching in the same system but without electrochemical impact and at air addition. The proposed direct current aided method is promising and more environmentally friendly compared to cyanide and even to sodium thiosulfate leaching.
\end{abstract}

\section{Introduction}

Our society development and our everyday life are impossible without the use of various metals under different forms. Mother-nature is their primary source. However, ore mining and beneficiation and metal extraction can considerably damage, pollute and change all environment compartments (soil, water, air). Waste rock from mining activities and tailings from minerals processing occupies vast areas and often considerably change the original landscape. For example, the tailings waste deposit Gornje Polje contains $12000000 \mathrm{~m}^{3}$ of minerals situated on an area of $500000 \mathrm{~m}^{2}$ of the Ibar Riverbank, Kosovo [1]. Another example - about 1.22 million $\mathrm{m}^{2}$ are affected by mining activity and over 2.84 million $\mathrm{m}^{2}$ by mining wastes in Bor basin, Serbia [2].

The waste rock (when it contains sulfide ores, especially pyrite at the exposure to oxidizing environment) can be a source of acid drainage. This, in its turn can solubilize different hazardous metals. Mineral processing tailings (i.e. useless silicate, oxide and sulfide minerals that are rejected during the ore processing) are generally released into tailings ponds and stored underwater to avoid the oxidizing process. However, usually, this is not the case for old (already abandoned) production activities that often are not recultivated at all or not correctly re-cultivated. These sites, similarly to the waste rock, may pose environmental problems [3]. On the other hand, often old tailings ponds, in which

* Corresponding author: marichim@mgu.bg 
waste from the enrichment of much more abundant ores has been deposited, contain useful metals in concentrations comparable to and even higher than the concentrations of these metals in the ores processed today. Such waste materials are classified as secondary resources. They contain unrecovered minor (high-tech or precious) metals and base metals. For example, it is reported that in the former times, gold recovery effectiveness was in the range of 35-60\%, depending on the ore characteristics and extraction techniques applied. This left in the wastes ores with an average gold content higher than today's cut-off grade of $0.5 \mathrm{~g} / \mathrm{t}$ [4]. Recovery of precious and base metals from tailings and waste rock represents a challenging task.

A process, based of bulk sulfidation and selective flotation, is proposed for reprocessing and recycling of the tailings in the Bor basin [2], containing on average $0.41 \% \mathrm{Cu}, 0.8 \mathrm{~g} / \mathrm{t}$ $\mathrm{Au}$ and $2.4 \mathrm{~g} / \mathrm{t} \mathrm{Ag}$. At laboratory level $98 \%$ recovery of copper and $87 \%$ of pyrite were achieved (with the grades of the obtained concentrates correspondingly $1.34 \%$ and 42.74 $\%)$. Recoveries of precious metals were not analyzed in this study. However, the classical mineral processing for copper recovery includes pyrite depression by lime that causes precious metals loss in tailings [5]. Low recovery of gold from old tailings at the $\mathrm{Au}-\mathrm{Ag}-\mathrm{Cu}$ Tiouit mine (Morocco) by classical flotation is reported recently [3], even when the process is optimized to achieve high recovery of sulfides (69-75\%) and decrease in the acidgenerating potential of the material.

The above-described examples point at the fact that the traditional mineral beneficiation, pyrometallurgical and hydrometallurgical methods that have been developed for the high-grade ores are often inefficient to recover metals from tailings and mining waste rock and new processes have to be developed [6].

It is reported that ammonia-thiosulfate-copper system is very effective at leaching gold from refractory materials [7]. Gold is oxidized to gold thiosulfate:

$$
\mathrm{Au}+2 \mathrm{~S}_{2} \mathrm{O}_{3}{ }^{2-}=\mathrm{Au}\left(\mathrm{S}_{2} \mathrm{O}_{3}\right)_{2}{ }^{3-}+\mathrm{e}^{-}
$$

It is found that the process is easier when ammonia thiosulfate is used, compared to sodium thiosulfate [8].

It this system copper (II) functions as a redox mediator in the ammonia - thiosulfate solutions used in gold leaching [9]:

$$
\mathrm{Au}+\mathrm{Cu}(\mathrm{II})=\mathrm{Au}(\mathrm{I})+\mathrm{Cu}(\mathrm{I})
$$

Further, $\mathrm{Cu}(\mathrm{I})$ is oxidized to $\mathrm{Cu}(\mathrm{II})$ by the oxygen available in the system. Presence of $\mathrm{Cu}$ (II) increases 18-20 times the leaching of gold. Ammonia that is available in the solution stabilizes $\mathrm{Cu}$ (II) in alkaline media by forming $\left[\mathrm{Cu}\left(\mathrm{NH}_{3}\right)_{4}\right]^{2+}$ complex and catalyzes the formation of $\left[\mathrm{Au}\left(\mathrm{S}_{2} \mathrm{O}_{3}\right)_{2}\right]^{3-}$ complex. Thiosulfate available in the system tends to decompose and the process is intensified by an increase in the temperature, thiosulfate and $\mathrm{Cu}$ (II) concentration and excessive oxygen. It is found that $\mathrm{pH}=9-10$ simultaneously stabilizes thiosulfate and $\left[\mathrm{Cu}\left(\mathrm{NH}_{3}\right)_{4}\right]^{2+}$ complex [10]. The use of copper-ammoniathiosulfate system, as a promising replacement for cyanidation, has attracted significant scientific interest; however its commercial application is very rare - mainly for carbonaceous gold ores [10 - 12]. Nowadays the thiosulfate leaching is used at commercial level for complex sulfur-carbon based ores, known as double refractory ores, at Barrick Company [13].

Electrooxidation of ores and concentrates was proposed as means for enhancing their leaching - for the recovery of molybdenum from molybdenite [14], copper from $\mathrm{Cu}$ concentrate [15], $\mathrm{Cu}$ from chalcopyrite concentrate [16]. Electrooxidation of pyrite was suggested as a process that could be applied for the treatment of refractory gold ores [17].

We have proposed and successfully applied an electrochemically aided (ECA) recovery of gold and silver from pyrite concentrates using copper-ammonia-thiosulfate system, 
enriched in oxygen from air [18]. Successful leaching of silver in sodium thiosulfate solutions, facilitated by applying a direct current was proposed. Anodic potentials were applied to guarantee the needed oxidizing conditions, instead of a chemical oxidant [19].

Application of direct current to make easy in situ leaching of gold from subeconomic ores, combined with electrokinetics, has been proposed recently [20, 21]. However, the lixiviant used was a mixture of iodide $\left(\mathrm{I}^{-}\right)$and tri-iodide $\left(\mathrm{I}_{3}{ }^{-}\right)$solution.

Recently, thiosulfate leaching was applied to extract gold from mining waste with an average gold content of $3 \mathrm{~g} / \mathrm{t}$ [22]. Lately the capability of the electrochemical leaching to extract REEs from the magnet waste has been shown [23].

The obtained results in the above mentioned works encouraged us to study the ability of direct current aided hydrometallurgical treatment for extracting valuable metals from old mixed mining and mineral processing waste.

\section{Method}

Material from old copper flotation tailings, mixed with some waste rock at the time of disposal, was used in our laboratory experiments. The flotation tailings were placed together with mining waste for 30-40 years in a natural land depression. Then the mining and mineral processing activities were abandoned without proper re-cultivation measures. The tailings contain pyrite that in contact with rainwater and air is a prerequisite for the formation of acid rock drainage and leaching of metals - pollutants. Also, the historic data pointed at the presence of gold and silver in the tailings, since pyrite was depressed by $\mathrm{Ca}(\mathrm{OH})_{2}$ addition. Magnetic separation and sulfide flotation with some modifications were attempted with the aim to recover copper concentrate, gold and silver from that material, however, unsuccessfully. The material was milled to achieve $>90 \%$ with particles size 80 $100 \mu \mathrm{m}$. The chemical analysis showed that the studied material contained in wt. \%: 1.56 $\mathrm{Cu}, 1.02 \mathrm{Zn}, 0.44 \mathrm{~Pb}, 11.3 \mathrm{Fe}$ and also $-6 \mathrm{~g} / \mathrm{t} \mathrm{Au}$ and $36 \mathrm{~g} / \mathrm{t} \mathrm{Ag}$. The X-ray analysis (made with BRUKER D2 Phaser, $\mathrm{Cu} / \mathrm{Ni}$ radiation) has revealed that the copper was present mainly as sulfides and oxides, iron - as oxides/hydroxides, lead - as sulfide and partially as carbonate and oxide, and zinc - as sulfide and oxide. Gold was mainly as micro inclusions in copper sulfides and silver - as micro inclusions in copper and lead minerals.

The material subjected to the treatment was placed in a glass reactor $(2 \mathrm{~L})$ at solid to liquid ratio of $400 \mathrm{~g}$ to $1 \mathrm{~L}$. The leaching liquid used was clean tap water (with the conductivity of $110 \mu \mathrm{S} / \mathrm{cm}$ ) to which were added $\left(\mathrm{NH}_{4}\right)_{2} \mathrm{~S}_{2} \mathrm{O}_{3}$ (p.a.) - $150 \mathrm{~g} / \mathrm{L}$ and 25 wt. \% ammonia solution (p.a.) to obtain and maintain a $\mathrm{pH}$ of 10 . This value was found as optimal by our preliminary experiments. The $\mathrm{pH}$ in the range of $10-10.6$ was also chosen by other authors $[7,22]$ to ensure enough high concentration of free ammonia (and hence - copper (II)) that is acting as the catalyst in the leaching process. The suspension was mixed with a mechanical stirrer (with a glass blade). The suspension was subjected to an electrochemical impact with the aid of insoluble titanium-based electrodes $\left(\mathrm{S}_{\mathrm{a}}=\mathrm{S}_{\mathrm{c}}\right)$ at the direct current density of $3 \mathrm{~mA} / \mathrm{cm}^{2}$ and liquid samples for analysis were taken at predetermined times. Experiments were carried out at room temperature.

A laboratory stabilized rectifier, with inbuilt ampere-meter, was used as an energy source in experiments with the electrochemical impact. A laboratory $\mathrm{pH}$-meter was used for $\mathrm{pH}$-measurements. An aquarium pump $(60 \mathrm{~L} / \mathrm{h})$ was used to introduce air into the reaction vessel in the experiments without an electrochemical impact but with air addition.

After solid/liquid separation, the liquid phase was subjected to electrowinning for one hour, with stainless steel wool cathode and graphite anode at the cathodic current density of $1 \mathrm{~mA} / \mathrm{cm}^{2}$ (preliminary determined as feasible one and in the range of used by the other authors $[7,22])$. The material deposited on cathode was collected and analyzed. 
The $\mathrm{pH}$ of the liquid phase left after the electrowinning was adjusted to 8.5 by addition of $\mathrm{H}_{2} \mathrm{SO}_{4}$ and analyzed. Metals concentrations reported in work were determined by ICPanalysis (for the solid material after its digestion by using aqua regia). The procedure of the experiments is shown in Fig. 1. The data are processed using the excel program.

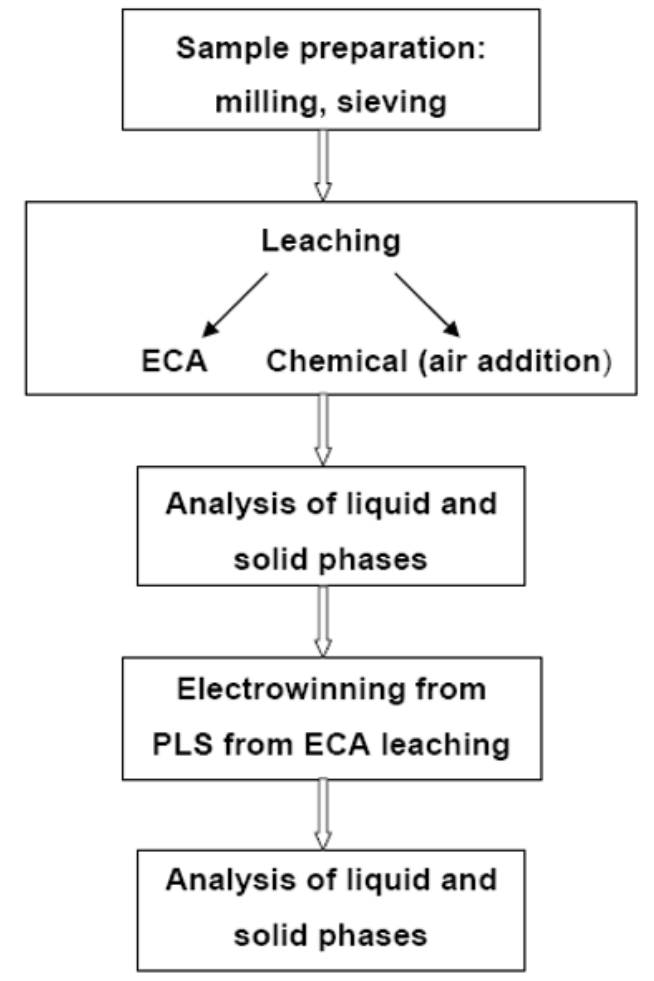

Fig. 1. Scheme of the experiments carried out.

\section{Results and discussion}

Data on the metals leaching (metal recovered in the solution as per cent of the initially available in the waste material) as function of time when an electrochemical impact was applied are presented in Fig. 2.

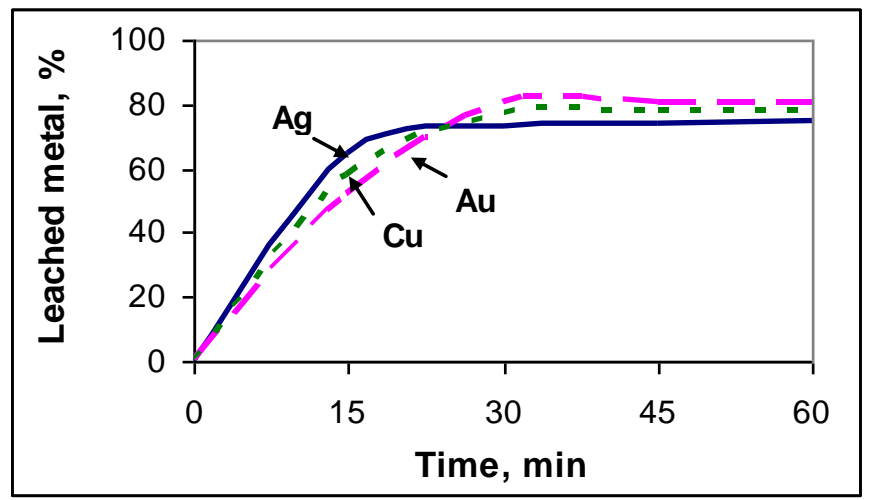


Fig. 2. Metal recovered in the solution (per cent of the initially available in the waste material) as function of time - electrochemically aided leaching.

Data on the same material leaching as function of time in the case without an electrochemical impact are shown in Fig. 3.

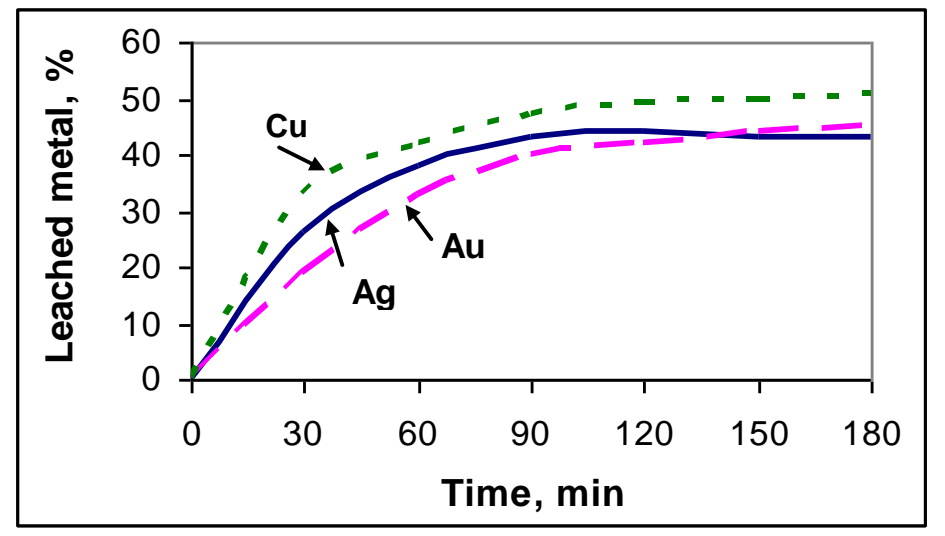

Fig. 3. Metal recovered in the solution (per cent of the initially available in the waste material) as function of time - chemical leaching.

As can be seen in Fig. 2, when an electrochemical impact is applied only $30 \mathrm{~min}$ are necessary to achieve leaching into the solution of over $75 \%$ (over $80 \%$ for $\mathrm{Au}$ ) of the metals initially available in the treated material. The leaching process is slower when the electrochemical impact is removed, and an oxidizing agent (air in this case) is supplied Fig. 3. Even more, the stage of little change is reached at lower extraction. In this case, the results are similar to the reported by other authors who do not apply an electrochemical impact [22]. Most probably, the electrochemical effect facilitates the disintegration and dissolution of copper from the material to a greater extent, compared to the addition of air. The elucidation of the exact mechanism needs further investigations. The presence of ammonia speeds the dissolution by the formation of stable copper ammonia complexes. In this way, the leaching of the copper available in the material ensures the presence of copper needed to act as a catalyst in the gold dissolution process. In addition, it could be hypothesized that the use of insoluble anode from one side prevents suspension contamination and from the other - ensures the formation of nascent oxygen species with high oxidative power [24] able to facilitate $\mathrm{Cu}(\mathrm{I})$ oxidation and the metals leaching from the studied material.

In both cases (Figs. 2 and 3) initially, the leaching rate of silver is higher compared to that of gold (the higher slope of the kinetic curve). Similar behaviour of gold and silver was also observed by other authors [25] who have shown that while initially, the silver dissolution rate is higher than that of gold in the later stages the situation is reversed (especially in the presence of oxygen and at higher content of silver in the treated material), finally leading to the lower extraction of silver than of gold (as \% of the initially available precious metals content).

Probably our good results in gold leaching can be at least partially attributed to the presence of silver in the treated waste material. It has been shown that silver has a positive effect in thiosulfate leaching of gold by ammoniacal copper (II) solution at room temperature [25].

Analysis of the liquid phase has revealed that the lead, zinc and iron concentrations are lower than the maximum permissible ones for wastewater from mining and beneficiation of 
metal ores, including inactive objects [26]. This finding points at the stability of the waste solid phase remained after the material leaching.

The analysis of the material deposited on cathode through electrowinning has shown that $91.7 \%$ of $\mathrm{Cu}, 92.1 \%$ of $\mathrm{Au}$ and $86.8 \%$ of $\mathrm{Ag}$ available in the solution were recovered in the solid phase. It is suitable for further metallurgical refining. Almost complete deposition of gold in one hour was observed from thiosulfate solution at similar current density, however, at significantly higher Au concentration, achieved after resin adsorption and elution [7]. Other authors found $98 \%$ gold recovery in $30 \mathrm{~min}$, though also in the more concentrated solution obtained by activated carbon adsorption and elution [22].

Data on concentrations of the relevant heavy metals in the liquid phase obtained after the electrowinning stage (after the addition of a small amount to $\mathrm{H}_{2} \mathrm{SO}_{4}$ to meet the legal requirements) are presented in Table 1.

Table 1. Results from analysis of the liquid phase after the electrowinning stage

\begin{tabular}{|c|c|c|}
\hline Parameter & Tested liquid phase & Legal requirements [26] \\
\hline $\mathrm{pH}$ & 8.5 & $6-9$ \\
\hline $\mathrm{Cu}, \mathrm{mg} / \mathrm{L}$ & $<0.5$ & $<0.5$ \\
\hline $\mathrm{Pb}, \mathrm{mg} / \mathrm{L}$ & $<0.2$ & $<0.2$ \\
\hline $\mathrm{Zn}, \mathrm{mg} / \mathrm{L}$ & $<2.0$ & $<2.0$ \\
\hline $\mathrm{Fe}, \mathrm{mg} / \mathrm{L}$ & $<3.5$ & $<3.5$ \\
\hline
\end{tabular}

As it can be seen, the water meets the requirements for the wastewater discharge into natural water bodies. The good results obtained from the laboratory experiments are a prerequisite for continuing the research at an extended laboratory level, which is under development.

\section{Conclusion}

The method proposed has shown promise in obviating an environmental problem associated with processing sulfide ores containing precious metals. The method revealed comprises electrochemically aided leaching in ammonia thiosulfate - copper system, where the treated material naturally releases the reaction redox mediator (copper II) under the treatment conditions. The used leaching reagent is not hazardous. Higher dissolution of gold and silver is achieved at room temperature when an electrochemical impact facilitates the process. The results obtained are comparable to the case when cyanide is used as a lixiviant. Also, high solubilization of copper that present is the waste material can be achieved. The solid phase left after the leaching is stable, with decreased copper content (compared to untreated material). High recovery is attained for gold, silver and copper in the material deposited on cathode from the pregnant leach solution, and the material is suitable for further metallurgical refining. The liquid phase left after the valuable metals electrowinning meets the legal requirements for wastewater discharging in surface water bodies. In conclusion, we can say that the initial tests give evidence that the proposed treatment merits further investigation.

\section{References}

1. J. Galjak, J. Đokić, G. Milentijević, I. Dervišević, S. Jović, Characterization of the tailing waste deposit "Gornje Polje", Optik - Int. J. Light and Electron Optics 215 164684 (2020) https://doi.org/10.1016/j.ijleo.2020.164684 
2. Z. S. Markovic, Z. Stirbanovic, R. Pantovic, F. Kongoli, Sustainable mining waste management in Bor basin, in Proceedings of Sustainable industrial processing summit / Shechtman international symposium, 2: Mineral Processing, 2014, Serbia - Ed. F. Kongoli, FLOGEN, 199 (2014) https://doi.org/10.13140/2.1.2257.4403

3. A. Nadeif, Y. Taha, H. Bouzahzah, R. Hakkou, M. Benzaazoua, Desulfurization of the old tailings at the Au-Ag-Cu Tiouit mine (Anti-Atlas Morocco), Minerals 9, 401 (2019) https://doi.org/10.3390/min9070401

4. B. O. Afum, D. Caverson, E. Ben-Awuah, A conceptual framework for characterizing mineralized waste rocks as future resource, Int. J. Mining Sci. Technol. 29, 429 (2019) https://doi.org/10.1016/j.ijmst.2018.07.002

5. E. Chanturiya, Influence of the chemical composition, texture of gold-bearing pyrite on recovery of pyrite with high gold content, in Proceedings of the XXIII International Mineral Processing Congress, 2006, Istanbul, Turkey, 1551 (2006) https://www.researchgate.net/publication/260506577

6. K. A. Komnitsas, Editorial for special issue "Recent advances in hydro- and biohydrometallurgy", Minerals 9, 424 (2019) https://doi.org/10.3390/min9070424

7. M. Jeffrey, J. Health, D. Hewitt, D. Brunt, X. Dai, A thiosulfate process for recovering gold from refractory ores which encompasses pressure oxidation, leaching, resin adsorption, elution, and electrowinning, in Proceedings of the Sixth International Symposium on Hydrometallurgy 2008, Eds. C. A. Young, P. R. Taylor C. G. Anderson, SME, 791 (2008) ISBN 9780873352666

8. I. Chandra, M. I. Jeffrey, An electrochemical study of the effect of additives and electrolyte on the dissolution of gold in thiosulfate solutions, Hydrometallurgy 73, 305 (2004) https://doi.org/10.1016/j.hydromet.2003.12.002

9. I. M. Ritchie, M. J. Nicol, W. P. Staunton, Are there any realistic alternatives to cyanide as a lixiviant for gold at the present time?, in C. Young, Cyanide: Social and economic aspects, The Minerals, Metal \& Materials Society Symposium, 12-15 February, New Orleans, USA, 427 (2001) http://researchrepository.murdoch.edu.au/id/eprint/30124

10. B. Xu, W. Kong, Q. Li, Y. Yang, T. Jiang, X. Liu, A review of thiosulfate leaching of gold: Focus on thiosulfate consumption and gold recovery from pregnant solution, Metals 7, 222 (2017) https://doi.org/10.3390/met7060222

11. D. M. Muir, M. G. Aylmore, Thiosulphate as an alternative to cyanide for gold processing-issues and impediments, Trans. Inst. Min. Metall. Sect. C 113, 2 (2004) https://doi.org/10.1179/037195504225004661

12. X. M. Zhang, G. Senanayake, A review of ammoniacal thiosulfate leaching of gold: An update useful for further research in non-cyanide gold lixiviants, Miner. Process Extr. Metall. Rev. 37, 385 (2016) https://doi.org/10.1080/08827508.2016.1218872

13. Y. Choi, A. G. Gharelar, Method for pre-treatment of gold-bearing oxide ores, Patent number: US 10161016, Assignee: Barrick Gold Corporation, 25.12.2018 (US, 2018)

14. D. S. Barr, R. E. Lindstrom, J. L. Hendrix, Control of the chlorate factor in electrooxidation leaching of molybdenum concentrates, Int J Miner Process, 2, 303 (1975) https://doi.org/10.1016/0301-7516(75)90025-3

15. G. A. Jáuregui, R. A. Reyes, Anodic electrooxidation of a copper concentrate, Hydrometallurgy, 17, 281 (1987) https://doi.org/10.1016/0304-386X(87)90059-4

16. S. Venkatachalam, Treatment of chalcopyrite concentrates by hydrometallurgical techniques, Miner Eng, 4, 1115 (1991) https://doi.org/10.1016/0892-6875(91)90087-C

17. F. Arslan, P. F. Duby, Electro-oxidation of pyrite in sodium chloride solutions, Hydrometallurgy 46, 157 (1997) https://doi.org/10.1016/S0304-386X(97)00009-1 
18. V. Panayotov, N. Nikolov, M. Panayotova, Method for extraction of precious metals from sulfide concentrates and secondary materials, BG 65703 B1, 31.07.2009 (Sofia, 2009)

19. D. A. Urzúa-Abarca, J. C. Fuentes-Aceituno, A. Uribe-Salas, J. C. Lee, An electrochemical study of silver recovery in thiosulfate solutions. A window towards the development of a simultaneous electroleachingelectrodeposition process, Hydrometallurgy 176, 104 (2018) https://doi.org/10.1016/j.hydromet.2018.01.017

20. E. Martens, H. Prommer, X. Dai, M. Z. Wu, J. Sun, P. Breuer, A. Fourie, Feasibility of electrokinetic in situ leaching of gold, Hydrometallurgy 175, 70 (2018) http://dx.doi.org/10.1016/j.hydromet.2017.10.020

21. E. Martens, H. Prommer, X. Dai, J. Sun, P. Breuer, A. Fourie, Electrokinetic in situ leaching of gold from intact ore, Hydrometallurgy 178, 124 (2018) https://doi.org/10.1016/j.hydromet.2018.04.003

22. S. Ubaldini, D. Guglietta, D. Vegliò, V. Giuliano, Valorization of mining waste by application of innovative thiosulfate leaching for gold recovery, Metals 9, 274 (2019) https://doi.org/10.3390/met9030274

23. I. Makarova, E. Soboleva, M. Osipenko, I. Kurilo, M. Laatikainen, E. Repo, Electrochemical leaching of rare-earth elements from spent $\mathrm{NdFeB}$ magnets, Hydrometallurgy 192, 105264 (2020) https://doi.org/10.1016/j.hydromet.2020.105264

24. S. Siahrostami, G. L. Li, V. Viswanathan, J. Nørskov, One or two-electron water oxidation, hydroxyl radical, $\mathrm{H}_{2} \mathrm{O}_{2}$ evolution, J. Phys. Lett. 8, 1157 (2017) https://doi.org/10.1021/acs.jpclett.6b02924

25. X. M. Zhang, G. Senanayake, M. J. Nicol, Beneficial effect silver in thiosulfate leaching of gold, in Proceedings of the Sixth International Symposium on Hydrometallurgy 2008, Eds. C. A. Young, P. R. Taylor C. G. Anderson, SME, 801 (2008) ISBN 9780873352666

26. Ordinance № 6 of 9.11.2000 on emission standards for the permissible content of harmful and dangerous substances in wastewater discharged into water bodies, Issued by the Minister of Environment and Water, the Minister of Regional Development and Public Works, the Minister of Health and the Minister of Economy, promulgated, SG, iss. 97 of 28.11.2000, amended and added, no. 24 of 23.03.2004, in force since 23.03.2004 (Sofia, Bulgaria, 2004) 